University at Albany, State University of New York

Scholars Archive

\title{
Creating Learning Outcomes from Threshold Concepts for Information Literacy Instruction
}

\author{
Allison Hosier \\ University at Albany, State University of New York, ahosier@albany.edu
}

Follow this and additional works at: https://scholarsarchive.library.albany.edu/ulib_fac_scholar

Part of the Information Literacy Commons

\section{Recommended Citation}

Hosier, Allison, "Creating Learning Outcomes from Threshold Concepts for Information Literacy Instruction" (2017). University Libraries Faculty Scholarship. 95.

https://scholarsarchive.library.albany.edu/ulib_fac_scholar/95

This Article is brought to you for free and open access by the University Libraries at Scholars Archive. It has been accepted for inclusion in University Libraries Faculty Scholarship by an authorized administrator of Scholars Archive. For more information, please contact scholarsarchive@albany.edu. 


\title{
Creating Learning Outcomes from Threshold Concepts for Information Literacy Instruction \\ Allison Hosier \\ University at Albany, State University of New York
}

\begin{abstract}
Author Note
Allison Hosier, Information Literacy Librarian, University at Albany, SUNY E-mail: ahosier@albany.edu

Phone: (518) 442-3574

This is an Accepted Manuscript of an article published by Taylor \& Francis in College and Undergraduate Libraries on November 18, 2016, available online:

http://www.tandfonline.com/10.1080/10691316.2017.1246396
\end{abstract}




\begin{abstract}
Threshold concepts theory and learning outcomes represent two different ways of thinking about teaching and learning. Finding a way to translate between the two is necessary for librarians who may wish to use concepts from the Framework for Information Literacy to shape their instruction. The following article outlines a process for transforming concepts from the "Scholarship as Conversation" frame into learning outcomes that the author developed as part of a tutorial project. This process can easily be adapted to a variety of instructional situations.
\end{abstract}

Keywords: threshold concepts, learning outcomes, information literacy 


\section{Creating Learning Outcomes from Threshold Concepts for Information Literacy Instruction}

Learning outcomes are an important component of teaching and learning. They set goals for instruction that inform the design of both the learning experience itself and the assessment that follows. When students meet learning outcomes, this information can be used to prove the value of the instruction given. When students fail to meet the outcomes in significant numbers, instructors work to understand why and revise their pedagogical approach as needed. Learning outcomes can be created and assessed for individual lessons or whole curricula. They are an essential piece of the current educational landscape.

The ACRL Standards for Information Literacy for Higher Education (2000) reflected this way of thinking by providing librarians with a set of prescribed learning outcomes and performance indicators which could be used to measure whether students had mastered the skills needed to be considered information literate. These learning outcomes influenced information literacy instruction and curriculum design at all levels. They gave librarians a common set of goals to work toward and a shared understanding of what information literacy looked like in practice.

By contrast, the ACRL Framework for Information Literacy (2015) gives librarians a set of frames that include threshold concepts, knowledge practices/abilities, and dispositions to work with but no learning outcomes. Rather, the task of creating learning outcomes based on these frames falls to librarians themselves, whether they are working on an individual or institutional level. The responsibility of creating such learning outcomes has some librarians feeling adrift. 
How to take on this challenge? How to scale ideas from the Framework to different instructional situations in which librarians might find themselves, including oneshot sessions, credit-bearing courses, tutorials, and more? There is no one right answer. However, the following article will detail a process the author developed for transforming concepts from the Framework into learning outcomes as part of a tutorial project. This process can easily be adapted to any instructional situation that requires such outcomes.

\section{Background}

In February 2015, members of the University at Albany's Information Literacy department attended a meeting of the Student Library Advisory Board. The goal of the meeting was twofold. First, to make students aware of the department's online learning opportunities, including its collection of tutorials. Second, to gather ideas for new tutorial projects. In the course of the conversation, the students present generated ideas for a number of possible tutorial topics. One that stood out was their desire to learn more about scholarly articles and their role in the research process.

The library had previously offered online materials that covered some aspects of this topic, including an electronic handout that outlined the characteristics of scholarly, trade, and popular publications and a video tutorial that demonstrated how to search for scholarly articles in a library database. The tutorial had recently been removed due to outdated content, but the handout was still available for independent use or as a supplement to related instruction.

It is conceivable that the students' needs could have been addressed by updating and better promoting these materials. The department had recently completed a similar project to revamp and refresh a popular plagiarism tutorial. However, the existing 
documents reflected an approach that placed more emphasis on skills and techniques than on foundational concepts concerning what scholarly articles are and how they might be used for research. This approach would not have fully addressed the students' expressed interests and so the author made the decision to begin an entirely new tutorial project.

The concept-based approach the author decided on was well-supported by the Framework, which at the time had only been recently finalized. The author decided to use the project as an opportunity to create a lesson that incorporated ideas from the Framework, a goal which needed to be carefully balanced with meeting the needs expressed by the members of the Student Library Advisory Board. The process that followed entailed creating initial learning outcomes that were then revised as the author's understanding of the relationship between threshold concepts, a key feature of the Framework, and learning outcomes evolved.

\section{Literature Review}

Threshold concepts and learning outcomes represent two different ways of thinking about teaching and learning.

Learning outcomes impose on students a predetermined endpoint for the learning process. The expectation is that students will be able to achieve the same learning goals in the same time frame and that they will be able to demonstrate their understanding in the same, measurable way. Once they have done so, they can continue on to the next phase of the curriculum. The more students that meet these goals, the more successful and valuable the instruction is generally considered to be.

By contrast, threshold concepts theory frames learning as a highly individual journey. To cross a threshold of understanding is a transformational process for a student 
that results in not only a cognitive shift but an ontological one. It is the transformational nature of threshold concepts that is often cited (Bryan and Karshmer 2015; Land and Meyer 2010; Townsend, Brunetti, and Hofer 2011) as the key difference between threshold concepts and learning outcomes but questions of their compatibility do not end there.

Ray Land and Jan H.F. Meyer, who established the foundation of threshold concepts theory, are critical of what Land, as quoted in an interview by Rhem (2013), refers to as a consumerist view of education, which is more concerned with moving students through a system than supporting deep learning. Land, Rattray, and Vivian (2014) reiterate this point in their discussion of a semiotic approach to threshold concepts. Learning outcomes can be seen as a characteristic of this system because they set uniform expectations on students, goals which must be adequately met so that they can then move on to the next step in the curriculum.

This learning outcomes-based approach to instruction assumes not only that students should experience the same shift in understanding as the result of the same instructional experience, but also that they are beginning the learning process on equal footing. According to Land and Meyer (2010), this assumption "that in a new module our learners commence, like athletes from a common start-line... and arrive collectively in a new conceptual space to countenance new conceptual thresholds" is inherently flawed (62). Finding ways to investigate and address "preliminal variations" in student understanding is a key challenge to designing instruction around threshold concepts (Meyer and Land 2006). 
Learning outcomes also undermine what Land, Cousin, Meyer, and Davies (2006) refer to as the "excursive" nature of learning. Learning is a journey that should have an intended direction but should also allow for deviation from the expected course so that the "eventual destination may be reached or revised" (Land, et al, 2006, 202). Learning outcomes do not allow for this type of flexibility.

Further complications arise when considering the temptation to conflate threshold concepts with learning outcomes. Adler-Kassner \& Wardle (2015) warn against this in the introduction to their book Naming What We Know: Threshold Concepts of Writing Studies. Threshold concepts are intended to be used as an influence on how a topic is taught rather than the explicit goal of instruction. Oakleaf (2014) describes threshold concepts as a basis for professional conversation rather than instructional design. This way of thinking proved to be highly valuable to the planning process for the tutorial project described in this article.

Reviewing these fundamental differences between threshold concepts and learning outcomes, it may seem that attempting to reconcile these different ways of thinking about teaching and learning is both naïve and inadvisable. However, finding a way to translate between the two is a necessary process because though the Framework, as a core document of the library profession, uses threshold concepts to present information literacy in a new and exciting way, learning outcomes and assessment are the accepted language of the current educational landscape. Learning outcomes may not always adequately capture the nuances of threshold concepts, but they can be a way to create goalposts as students make their way through what Rhem (2013) describes as "the 
space between the first step over the threshold and the last step out of confusion and uncertainty" (para. 1).

There are relatively few examples in the literature that discuss how to go about this translation process. In cases that do exist, the details are vague and some address the creation of learning outcomes only at the program level. Oakleaf (2014) provides a set of useful guidelines for assessing threshold concepts that was important to this project, but includes no specific recommendations for how to first create learning outcomes. Jacobson and Gibson (2015) include example learning outcomes based on threshold concepts in their set of recommendations on how to begin implementing the Framework. Porter (2014) combines ideas about threshold concepts, millennial research strategies, and learning theory to design an information literacy program to address institutional learning goals. Carncross (2016) and Witek (2015) both explore the challenge of revising existing learning outcomes with the Framework in mind.

This article seeks to fill a gap in the existing literature by outlining the specific process by which the author created learning outcomes based on a threshold concept for an information literacy lesson delivered as an online tutorial. This process is outlined in the following section.

\section{Process and Methods}

The process for creating learning outcomes based on the Framework began with choosing a frame (threshold concept) on which to focus content. Next, the author created initial learning outcomes that prioritized the needs expressed by the members of the Student Library Advisory Board. In a process similar to that described by Carncross (2016) and Witek (2015), these initial learning outcomes were then revised using the 
chosen frame as a lens. The content of the tutorial was based on these revised learning outcomes and a method for assessment of student learning in relation to the outcomes was devised and built into the tutorial. Each of these steps is considered in more detail below.

\section{Choosing a Frame}

The first step of this project was to read through the description of each frame in the Framework and decide which one might provide a useful focus for the tutorial based on the author's conversation with the members of the Student Library Advisory Board. This was no easy task as multiple frames could offer potentially interesting and creative angles from which to approach the broad topic of scholarly articles, including "Information Creation as a Process" and "Authority is Constructed and Contextual." In this case, the decision to focus the instruction primarily on a single frame was influenced by literature on best practices for video tutorials, which generally suggests narrowing the focus of content and placing limits on a tutorial's length in order to avoid cognitive overload (Slebodnik and Riehle 2009).

Ultimately, the "Scholarship as Conversation" frame was chosen as the lens through which the content would be presented. As described in the Framework, "Scholarship as Conversation" lays an excellent foundation on which to build concepts about the role of scholarly articles in the research process for students. The author had a particular interest in Fister's (1993) argument that librarians tend to overlook the rhetorical aspects of research in their instruction, concentrating instead on teaching students how to find sources. Such an approach may lead to a fundamental misunderstanding for students that "finding sources" is also about "finding a right 
answer." The "Scholarship as Conversation" frame directly challenges this notion in a way that could also help students better understand the role of scholarly articles in research.

It should be noted that prior to researching threshold concepts in more depth, the author's intention was to first choose a frame and then create a tutorial using that frame as the topic such that the working title for this project was the "Scholarship as Conversation Tutorial." In the past, the author used a similar approach to create tutorials based on ideas from the Standards. Indeed, one does not have to look far to find tutorials and other librarian-created instructional materials based on the Standards that reflect such a strategy. For the more skill-based Standards, this worked well but turned out to be a less comfortable fit for the more conceptual Framework.

As the project evolved, the author came to use the frame as a lens through which to view the planned content rather than the topic of the tutorial. This approach is more in line with Adler-Kassner \& Wardle's (2015) discussion of using threshold concepts as an influence for instruction rather than the explicit goal. A tutorial that taught students about the "Scholarship as Conversation" frame may have contained useful ideas but it would not have satisfactorily addressed the request that had set this project into motion in the first place. Fulfilling this request was the author's priority.

\section{Creating Initial Learning Outcomes}

Good instructional design practice typically involves identifying the goals of instruction before planning the content (Wiggins and McTighe 2005a). Though this backward design process is more commonly applied to a larger unit or curriculum rather than a single lesson (Wiggins and McTighe 2005b), applying it here was a useful exercise 
in that it worked as a reminder that though this project provided an opportunity to integrate ideas from the Framework into an online tutorial, the real goal was to meet students' needs. The next step in the planning process for the tutorial was then to create a set of initial learning outcomes that prioritized these needs. Though the chosen frame was a factor, it did not play a significant role until the revision process that followed, as detailed in the next section.

The timeline for this project did not allow for the type of in-depth needs analysis that is normally recommended as part of the instruction design process, as described by Brown and Green (2011). Instead, the author used notes from a conversation with the Student Library Advisory Board to determine what the goals of the instruction should be. Though there are obvious shortcomings in treating the views of the Student Library Advisory Board members as representative of the larger student population, the purpose of this Board is to provide a student perspective on library-related issues which can then be used to influence decisions within the library, so it was not unprecedented to use information gleaned from them in this way.

Tutorial topic ideas were elicited from Student Library Advisory Board meeting as part of a think/pair/share activity in which students first brainstormed potential topics on their own before sharing them with a partner and then reporting out to the group. More than one report included "peer-reviewed articles" among their list of ideas. The author's notes from this meeting suggest that when students were asked to elaborate on what exactly they were interested in learning about peer-reviewed articles, it became clear that students wanted to know not only how to identify and access these articles, but also how to understand and analyze their content as part of their research. 
Based on these notes, the author created the following initial learning outcomes to describe the desired results of the instruction provided by the planned tutorial:

1. Students will be able to identify the role of a scholarly article in the research process (LO \#1).

2. Students will be able to recognize the function of common elements of a scholarly journal article (LO \#2).

3. Students will be able to distinguish between a scholarly article and a nonscholarly article (LO \#3).

These learning outcomes describe fairly standard goals for basic instruction on scholarly journal articles. While they may have been adequate on their own, filtering them through the lens of the "Scholarship as Conversation" frame further enhanced the goals of the instruction, which in turn enhanced the content.

\section{Revising the Learning Outcomes}

The initial learning outcomes were formulated independent of the chosen frame in order to ensure that students' needs were being prioritized. Once these learning outcomes had been established, the author then worked to revise them using ideas from the "Scholarship as a Conversation" frame as a conceptual anchor. What would these same goals look like when filtered through the lens of the relevant threshold concept?

The knowledge practices and dispositions outlined for the "Scholarship as a Conversation" frame served as a useful starting point. According to these suggestions, someone who understands the conversational nature of scholarship recognizes that this conversation is ongoing, that it takes place in a variety of venues, and that they are a potential contributor to that conversation (Association of College \& Research Libraries 
2015). The description of the frame also highlights the importance of recognizing the need to negotiate meaning from competing perspectives. The challenge was to find ways to apply these ideas to each of the existing learning outcomes.

For LO \#1, it was necessary to consider what placing scholarly articles in a broader rhetorical context could tell students about their role in the research process, beyond simply defining peer review and outlining their other discrete qualifications as credible sources. In order to achieve this, the author formulated a new learning outcome that emphasized that scholarly articles were one piece of a larger conversation, representing the views of disciplinary experts whose goal is to advance knowledge in their field. Their role in research is to provide a variety of research-based perspectives from which the student must negotiate meaning. Explaining the nature of scholarly articles in this way would be the first step in addressing students' request for help learning how to analyze information in these sources.

Based on this thought process, LO \#1 was revised as follows:

1. Students will be able to describe the scholarly article as a piece of an ongoing scholarly conversation in which a variety of perspectives may be represented and meaning must be negotiated.

Understanding the nature of a scholarly article is key to being able to analyze the information in it, but learning about the common elements of a scholarly article (abstract, literature review, methods/results, etc.) is also important to this goal. To reshape LO \#2 to better reflect ideas from the "Scholarship as Conversation" frame, the author looked to McMillen and Hill (2004), who describe introducing students to the rhetorical of aspects of research by framing them as a conversation that is being conducted in a foreign 
language. Someone who is trying to understand a language that is unfamiliar to them might begin by looking for patterns. The common building blocks of a scholarly article are those patterns. Once a student recognizes these patterns and begins to understand their function, they start to become fluent in the "language" of scholarly articles (though not necessarily the jargon associated with them). Their analysis of the article's content will then become more efficient and effective. As their expertise develops, they can transfer this knowledge to scholarly articles that use different patterns or begin to use those patterns in their own writing.

The goal stated in LO \#2 was revised to reflect this perspective. The modified outcome reads:

2. Students will be able to recognize the common building blocks of a scholarly article in order to become an effective and efficient reader of the scholarly conversation.

The revision process for $\mathrm{LO} \# 3$ was the most challenging because it required translating between a threshold concept and an outcome based primarily on skill. The most practical way to teach students how to identify scholarly articles in a search for information was to demonstrate such a search and highlight clues to the article's scholarly nature such as author affiliations, article length, and abstract content. In materials previously offered by the library, these clues had been presented as a simple checklist of what might seem to a student like disparate items. When thought about in a more rhetorical context, these characteristics can be explained in a more connected way. For example, the title of a scholarly article tends to use jargon, which signals that the 
intended audience for the article is disciplinary experts who understand this specialized language. This information circles back to the first two learning outcomes in key ways.

LO \#3 was changed to the following:

3. Students will be able to distinguish between scholarly articles and other types of contributions to the scholarly conversation in a search for information by using their knowledge of the role scholarly articles play in the scholarly conversation and the common characteristics resulting from that role.

Revising the initial learning outcomes using ideas from the "Scholarship as Conversation" frame was a useful exercise not only for thinking about how to translate between threshold concepts and more traditional learning goals but also for ultimately enhancing the planned content for the tutorial.

\section{Creating the Tutorial}

Following the revision of the three learning outcomes, the planning process for the content and structure of the tutorial could begin in earnest. The first concern was whether all three learning outcomes could comfortably and realistically be addressed in a single, relatively brief tutorial, especially considering the aforementioned recommended best practices (Slebodnik and Riehle 2014) regarding the content and length of tutorials. To solve this issue, the author created a script for what became known as the "Working with Scholarly Articles" tutorial that divided the content into three sections. The content of each section focused on one of the learning outcomes. The first section, "What is a Scholarly Article?" addressed LO \#1 while the second, "Reading a Scholarly Article," focused on LO \#2, and the third "Finding and Identifying Scholarly Articles" related 
directly to LO \#3. The script and tutorial were structured so that these sections could be watched separately or as a whole, depending on the needs and interests of the viewer.

The author used Techsmith's Camtasia software to create the tutorial, a narrated video with a combination of animated text and images to represent the more conceptbased content and screen capture to demonstrate the skill-based content. Because of the tutorial's emphasis on concepts, it became important to locate quality images to illustrate relatively abstract ideas. Pixabay, an online database for searching copyright-free images, became an important resource for this purpose.

\section{Assessing the Learning Outcomes}

In literature on instructional design, learning outcomes and assessment go handin-hand. It is not enough to establish goals for instruction. Those goals must be measured and refined over time.

Oakleaf (2014) explores the relationship between assessment and threshold concepts and provides a set of useful guidelines for creating such an assessment. Further exploration of this relationship within the constraints of a tutorial project may be a worthwhile topic for future study.

For this project, the author consulted a number of research studies on the assessment of tutorial design and student learning (Appelt and Pendell 2010; Befus and Byrne 2011; Betty 2008; Blummer 2007; Bracke and Dickstein 2002; Dent 2003; Ergood, Padron, and Rebar 2012; Germek 2012a; Germek 2012b; Henrich and Atterbury, 2012 Jackson 2006; Lechner 2005; Lindsay, Cummings, Johnson, and Scales 2006; Stiwinter 2013) for ideas. An informal exploration of the tutorials available on ACRL's 
Peer-Reviewed Instructional Materials Online database also influenced decisions about how assessment would be built into the tutorial.

In this case, two methods of assessment were used. The first was to place a multiple choice "Check Your Knowledge" question at the end of each section (Figure 1). Each question relates directly to the learning outcome for that section of the tutorial. A correct answer will bring the student to a screen that allows them to either exit the tutorial or move on to the next section (Figure 2).

The purpose of a scholarly article is best described as:

A Informing the general public about advances in scholarly research

B Finding the right answer to explain phenomena through valid research studies and experiments.

C Advancing knowledge in a field and contributing to an ongoing scholarly conversation.

D Giving authors a venue for submitting their work for the peer review process, which adds a layer of credibility to their article. 


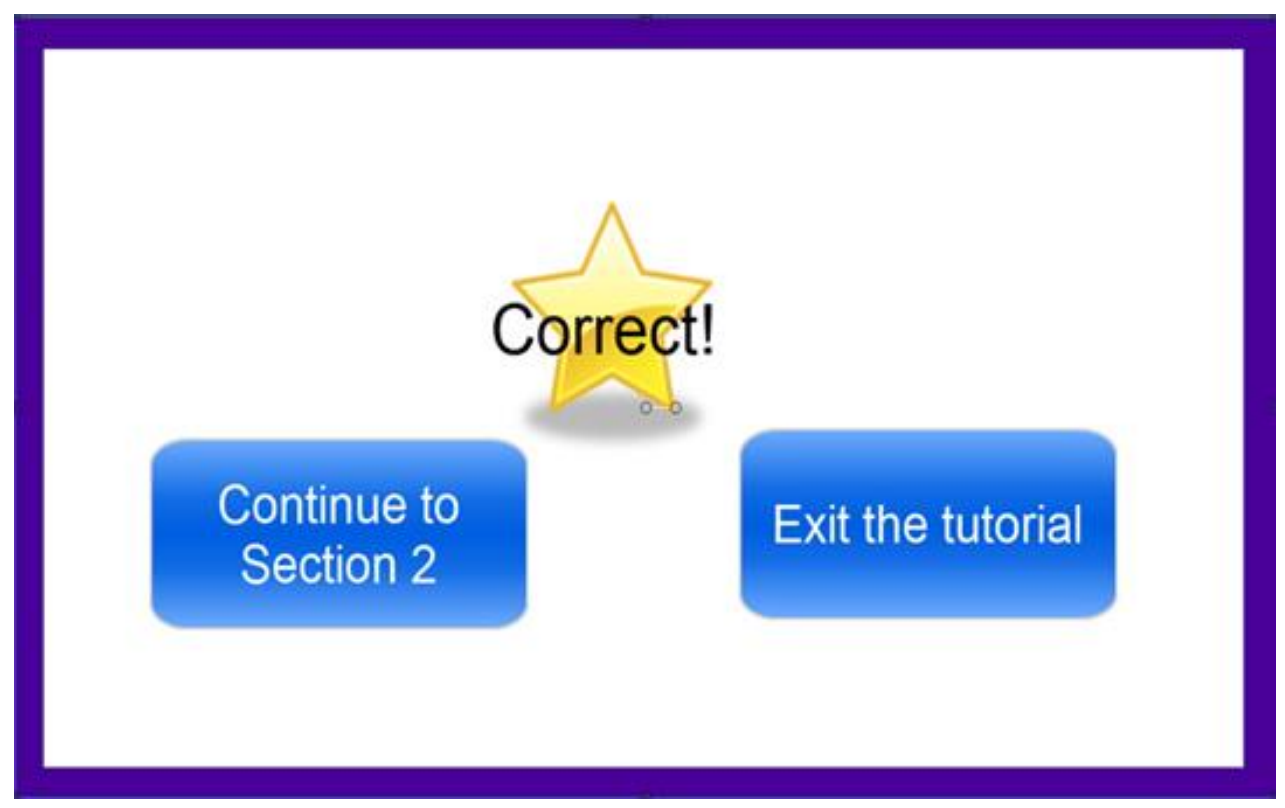

[FIGURE 2 - Correct Answer Screen]

An incorrect answer triggers a brief review which summarizes the content of the section for the viewer. This brief review ends with a choice. The user can either indicate that they understand the content and would like to move on or gives them the option to review further before answering the question again (Figure 3).

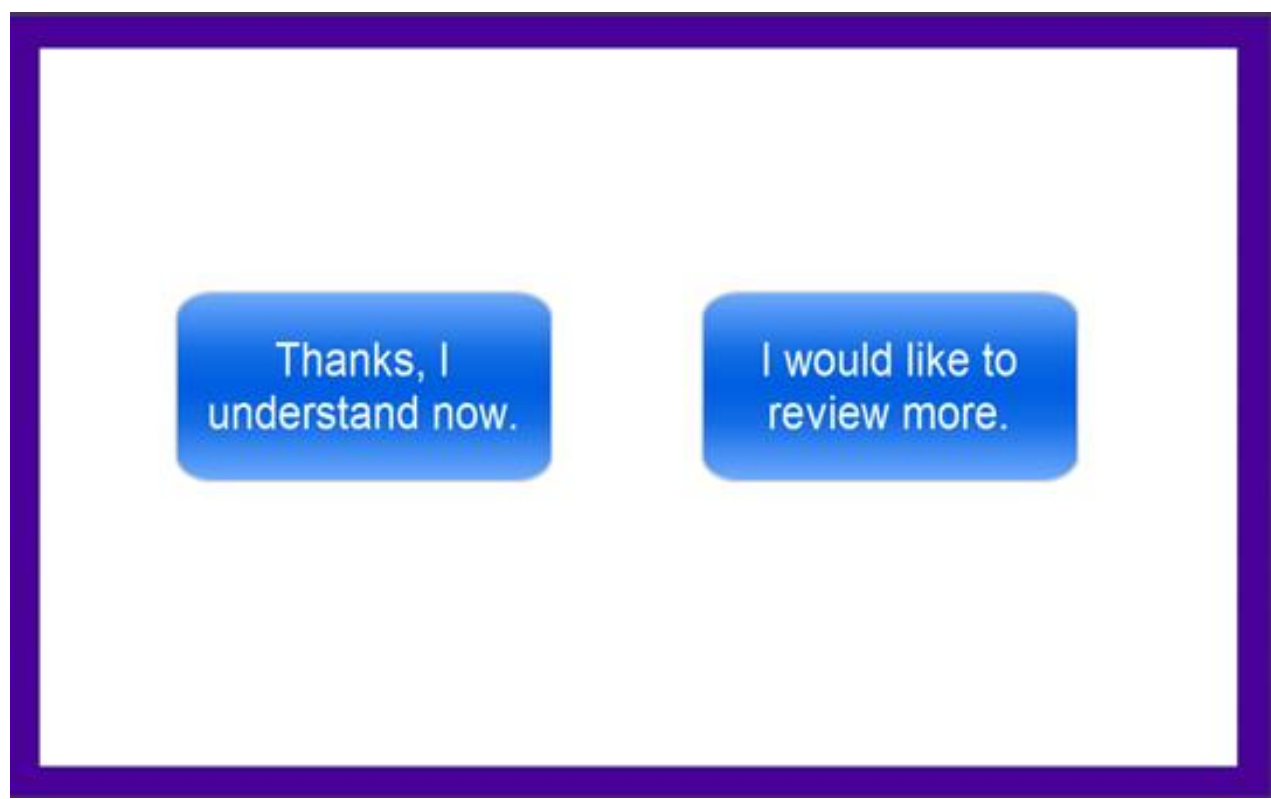




\section{[FIGURE 3 - Review Option]}

The author used a combination of buttons, hot spots, and markers in Camtasia to create these separate paths. However, a method has not yet been devised to track students' exact paths through the tutorial and so though these "Check Your Knowledge" questions serve as useful checkpoints for understanding, their use for assessment purposes is limited.

The second assessment comes at the end of the tutorial. Students completing the tutorial as part of a course assignment are required to fill out a form in order to get credit. In addition to contact information, the form, which was created in Drupal, includes two questions typical of a simple assessment known as a "one minute paper." Students must indicate one thing they learned as a result of the tutorial and one thing they still have a question about. The more reflective nature of this assessment is intended to be in line with recommendations regarding the assessment of threshold concepts (Jacobson and Gibson 2015, Land and Meyer 2010; Oakleaf 2014). The information students enter on this form is sent automatically to the students' course instructor, who can use it as proof that the student completed the assignment. The librarian also has access to this information via a database on the back end and can use students' responses to gauge the tutorial's effectiveness and refine its content over time as needed.

\section{Limitations and Future}

The "Working with Scholarly Articles" tutorial became available on the University at Albany University Libraries' website in summer 2015. It was promoted via e-mail to faculty members who were known users of the library's tutorials. The author also created slides to promote the tutorial both on the main page of the library's website 
and on the site for the Information Literacy department. Use of the tutorial was low in the fall semester but grew in spring. The Information Literacy department is currently undertaking a project to reorganize the instructional content of their website in the hopes of making resources more visible and to increase use.

This article details the author's efforts to translate the "Scholarship as Conversation" threshold concept into a set of learning outcomes that not only reflect ideas from the Framework but also meet students' needs. Though the author had some knowledge of instructional design practices, no formal instructional design model was employed as part of this project. A future project or study could refine the author's approach by applying such a model.

More work also needs to be done to assess student learning as a result of the tutorial. Scales, Nicol, \& Johnson (2014) describe a process for coding student responses to a survey and using the aggregate information to assess a tutorial's effectiveness. A similar process could be used to analyze the information from the spreadsheet generated by the form at the end of the "Working with Scholarly Articles" tutorial. Combined with Oakleaf (2014)'s recommendations for creating a model response as a tool to measure student learning, such an analysis could inform future plans to refine the tutorial's content or structure. A research study could potentially be built around such an analysis, though factors such as the lack of anonymity of responses in the current system would need to be addressed before conducting such a study.

A tutorial offers limited opportunities when it comes to the depth of instruction. When the Framework was first introduced, librarians expressed concern that the ideas in it were too big to be addressed in a one-shot session, much less a brief tutorial. This 
article shows that it is possible to use ideas from the Framework to create learning outcomes that are appropriate to this mode of instruction. A tutorial may not be enough on its own to help students across a threshold of understanding that will ultimately lead them to be able to think like expert researchers, but it can at least bring the threshold into view by introducing students to a more sophisticated understanding of the topic than they may have previously considered. That said, the next step here is to begin translating frames into learning outcomes for other instructional situations, including course-related and credit-bearing instruction.

\section{Conclusion}

Learning outcomes describe what students will be able to do as a result of instruction. Used in conjunction with assessment, they also provide a measure for the success of that instruction.

As librarians work to create or revise learning outcomes at the programmatic or institutional level to reflect concepts from the new Framework, it is also important to find strategies for adapting these ideas into learning outcomes that can be applied to day-today instruction, whether that instruction is delivered as part of an online tutorial or in the classroom.

This article has sought to explore the difficulties inherent in translating between two different ways of thinking about teaching and learning and to explore a process for doing so. This process, which involves choosing a frame, creating initial learning outcomes to meet students' needs, and then revising those outcomes using ideas from the Framework, is a useful exercise for better understanding how these frames can enhance librarians' teaching in new and exciting ways. 


\section{References}

Adler-Kassner, L., and Wardle, E. 2015. "Naming What We Know: The Project of This Book.” In Naming What We Know: Threshold Concepts of Writing Studies edited by L. Adler-Kassner and E. Wardle, 1- 11. Boulder: University Press of Colorado.

Appelt, K. M., and Pendell, K. 2010. “Assess and Invest: Faculty Feedback on Library Tutorials." College \& Research Libraries 71(3):245-53.

Association of College \& Research Libraries. 2000. Information Literacy Competency Standards for Higher Education. Chicago: American Library Association. http://www.ala.org/acrl/standards/informationliteracycompetency

Association of College \& Research Libraries. 2015. Framework for Information Literacy for Higher Education. Chicago: American Library Association. $\underline{\text { http://www.ala.org/acrl/standards/ilframework }}$

Befus, R., and Byrne, K. 2011. "Redesigned with Them in Mind: Evaluating an Online Library Information Literacy Tutorial.” Urban Library Journal 17(1):1-26.

Betty, P. 2008. “Creation, Management, and Assessment of Library Screencasts: The Regis Libraries Animated Tutorials Project.” Journal of Library Administration 48(3/4):295-315.

Blummer, B. 2007. “Assessing Patron Learning from an Online Library Tutorial." Community \& Junior College Libraries 14(2):121-38.

doi:10.1080/02763910802139397

Bracke, P. J., and Dickstein, R. 2002. "Web Tutorials and Scalable Instruction: Testing the Waters.” Reference Services Review 30(4):330-37. 
Brown, A., and Green, T.D. 2011. "Needs Analysis.” The Essentials of Instructional Design $2^{\text {nd }}$ ed., 40-55. Boston: Pearson.

Bryan, J. E., and Karshmer, E. 2015. "Using IL Threshold Concepts for Biology." College \& Research Libraries News 76(5):251-55.

Carncross, M. 2015. "Redeveloping a Course with the Framework for Information Literacy for Higher Education." College \& Research Libraries News 76(5): 24873.

Dent, V. F. 2003. "Innovation on a Shoestring: An All-Virtual Model for Self-Paced Library Orientation on an Urban Campus." College \& Undergraduate Libraries 10(2):29-44. doi:10.1300/J106v10n02・03

Ergood, A., Padron, K., and Rebar, L. 2012. "Making Library Screencast Tutorials: Factors and Processes." Internet Reference Services Quarterly 17(2):95-107. doi:10.1080/10875301.2012.725705

Fister, B. 1993. "Teaching the Rhetorical Dimensions of Research.” Research Strategies 11(4):211-19.

Germek, G. 2012a. "Empowered Library eLearning: Capturing Assessment and Reporting with Ease, Efficiency, and Effectiveness." Reference Services Review 40(1):90-102. doi:10.1108/00907321211203658

Germek, G. 2012b. "The Lack of Assessment in the Academic Library Plagiarism Prevention Tutorial." College \& Undergraduate Libraries 19(1):1-17. doi:10.1080/10691316.2012.652547 
Henrich, K. J., and Attebury, R. I. 2012. "Using Blackboard to Assess Course-Specific Asynchronous Library Instruction." Internet Reference Services Quarterly 17(3/4):167-179. doi:10.1080/10875301.2013.772930

Jackson, P. A. 2006. "Plagiarism Instruction Online: Assessing Undergraduate Students' Ability to Avoid Plagiarism.” College \& Research Libraries 67(5):418-28.

Jacobson, T. E., and Gibson, C. 2015. "First Thoughts on Implementing the Framework for Information Literacy.” Communications in Information Literacy 9(2):102-10.

Land, R., Cousin, G., Meyer, J.H.F., and Davies, P. 2006. "Conclusion: Implications of Threshold Concepts for Course Design and Evaluation." In Overcoming Barriers to Student Understanding: Threshold Concepts and Troublesome Knowledge, edited by J.H.F. Meyer and R. Land, 19-32. London: Routledge.

Land, R., \& Meyer, J.H.F. 2010. “Threshold Concepts and Troublesome Knowledge (5): Dynamics of Assessment." In Threshold Concepts and Transformational Learning, edited by J.H.F. Meyer, R. Land, and C. Baillie, 61-79. Rotterdam: Sense Publishers.

Land, R., Rattray, J., and Vivian, P. 2014. "Learning in the Liminal Space: A Semiotic Approach to Threshold Concepts." Higher Education 67(2):199-217.

Lechner, D. L. 2005. “Graduate Student Research Instruction: Testing an Interactive Web-Based Library Tutorial for a Health Sciences Database." Research Strategies 20(4):469-81. doi:10.1016/j.resstr.2006.12.017

Lindsay, E., Cummings, L., Johnson, C., and Scales, B. 2006. "If You Build It, Will They Learn? Assessing Online Information Literacy Tutorials.” College \& Research Libraries 67(5):429-45. 
McMillen, P. S., and Hill, E. 2004. "Why Teach 'Research as a Conversation' in Freshman Composition Courses? A Metaphor to Help Librarians and Composition Instructors Develop a Shared Model.” Research Strategies 20(1):322. doi:10.1016/j.resstr.2005.07.005

Meyer, J.H.F., and Land, R. 2006. "Threshold Concepts and Troublesome Knowledge.” In Overcoming Barriers to Student Understanding: Threshold Concepts and Troublesome Knowledge, edited by J.H.F. Meyer and R. Land,. 19-32. London: Routledge.

Oakleaf, M. 2014. “A Roadmap for Assessing Student Learning Using the New Framework for Information Literacy for Higher Education." Journal of Academic Librarianship 40(5):510-14. doi:10.1016/j.acalib.2014.08.001

Porter, B. 2014. “Designing a Library Information Literacy Program Using Threshold Concepts, Student Learning Theory, and Millennial Research in the Development of Information Literacy Sessions." Internet Reference Services Quarterly 19(3/4):233-44. doi:10.1080/10875301.2014.978928

Rhem, J. 2013. "Threshold Concepts and Troublesome Knowledge.” National Teaching and Learning Forum Newsletter 22(4). https://teachingcommons.stanford.edu/teaching-talk/and-after-students-get-it$\underline{\text { threshold-concepts }}$

Scales, B. J., Nicol, E., and Johnson, C. M. 2014. "Redesigning Comprehensive Library Tutorials." Reference \& User Services Quarterly 53(3):242-52. 
Slebodnik, M., and Riehle, C. F. 2009. "Creating Online Tutorials at Your Libraries: Software Choices and Practical Implications." Reference \& User Services Quarterly 49(1):33-51.

Stiwinter, K. 2013. "Using an Interactive Online Tutorial to Expand Library Instruction." Internet Reference Services Quarterly 18(1):15-41. doi:10.1080/10875301.2013.777010

Townsend, L., Brunetti, K. and Hofer, A. R. 2011. "Threshold Concepts and Information Literacy." portal: Libraries and the Academy 11(3):853-69.

Wiggins, G., and McTighe, J. 2005a. "Backward Design.” Understanding by Design $2^{\text {nd }}$ ed., 13-34. Alexandria, VA: Pearson.

Wiggins, G., and McTighe, J. 2005b. "Introduction." Understanding by Design $2^{\text {nd }}$ ed., 1-12. Alexandria, VA: Pearson.

Witek, D. "'Sunrise, Sunset': A Reflection on Assessment and the Framework for Information Literacy for Higher Education," ACRLog. 2015. http://acrlog.org/2015/01/27/sunrise-sunset-a-reflection-on-assessment-and-theframework-for-information-literacy-for-higher-education/ 